Crawford, J. S. (1963). Brit. med. 7., 2, 119.

Davidson, J. A. (1962). Ibid., 2, 951 .

Heyns, O. S. (1959). F. Obstet. Gynaec. Brit. Emp., 66, 220.

Hingson, R. A., Culi, W. A., and Benzinger, M. (1961). Anesth. Analg. Curr. Res., 40, 119.

Johnstone, M. (1963). Proceedings of the Symposium on Methoxyflurane, p. 35. Queensborough, Kent

Lamaze, F. (1958). Painless Childbirth. London.

McAneny, T. M., and Doughty, A. G. (1963). Anaesthesia, 18, 488.
Mapleson, W. W. (1963). In Uptake and Distribution of Anesthetic Agents, edited by E. M. Papper and R. J. Kitz, p. 104. New York. Medical Research Council (1954). The Use of Trilene by Midwives, Memorandum No. 30. London.

Minnitt, R. J. (1934). Brit. med. F., 1, 501.

Romagnoli, A., and Korman, D. (1962). Canad. Anaesth. Soc. F., 9, 414.

Sharpless, S. K. (1965). In The Pharmacological Basis of Therapeutics, edited by L. S. Goodman and A. Gillman, 3rd ed., p. 132. New York.

\title{
Patients who Reside in Common Lodging-houses
}

\author{
RICHARD SCOTT,* M.D., D.P.H.; P. G. GASKELL,* M.B., CH.B. \\ D. C. MORRELL, ${ }^{*}$ M.B., B.S., M.R.C.P., D.OBST.R.C.o.G.
}

Brit. med. F., 1966, 2, 1561-1564

Common lodging-houses exist in many of our larger cities and are licensed by the local health authority. A night's lodging is cheap and the facilities provided are correspondingly limited. Many clients pay for one night at a time.

There is surprisingly little up-to-date information about the size of the lodging-house population in this country, and its demands and needs in respect of medical or social care. Laidlaw (1956) traced the growth of the lodging-house system. $\mathrm{He}$ made a detailed study of lodging-houses in Glasgow, which at that time accommodated over 7,000 persons, of whom he interviewed 800. Sargaison (1954) surveyed living conditions in lodging-houses in Belfast, and reported on the results she obtained from a social interview with a series of 371 inhabitants over the age of 60 years. Merfyn Turner (1960) gave an interesting commentary on a London lodging-house and some of its inhabitants as seen by a trained sociologist. We require a considerable investment in sociological and epidemiological techniques if we are to bring these studies up to date and to extend them.

Clinical studies relating to the lodging-house population usually reflect the specialist's interest-for example, Whiteley (1955) reported on the psychiatric diagnosis of 100 men admitted to an observation ward from three lodging-houses in London, while Edwards et al. (1966) studied alcoholism in a sample group of 51 down-and-out men who were regular patrons of a soup kitchen in Stepney.

General practitioners and hospital doctors working in casualty and outpatient departments not infrequently encounter individuals residing in common lodging-houses. Since they see a broader spectrum of disease than that presenting in more specialized departments, it is worth while to look at records which can be obtained from such sources.

\section{Method}

\section{The Sample}

This study took place in a general practice in Edinburgh. In that city there exists lodging-house accommodation for approximately 1,000 persons. Five lodging-houses are situated within a radius of a quarter of a mile of the practice premises, and, though their occupants are free to consult any doctor in the area, substantial numbers of them use this practice. As a consequence, and some time before the study began, when the practice reorganized its appointment system we reserved one bour each morning during which individuals residing in common lodging-houses could present themselves as temporary patients without prior appointment.

\footnotetext{
* Department of General Practice, Edinburgh University.
}

The sample used for this study simply consisted of all patients residing in common lodging-houses who so presented themselves during a period of six months (March-August 1964). This consecutive series of 310 persons comprised 210 who had attended on at least one previous occasion, together with 100 who were seen for the first time ever during the period of the survey.

Two categories of data were collected during the survey: (1) information recorded in respect of each person on the first occasion on which he was seen during the period; and (2) data recorded at each consultation with each patient throughout the survey period.

The nature of the information available to the doctor at the first consultation varied; in respect of the new patients no information at all existed, but with regard to two-thirds of the sample at least some information was available before the patient was seen for the first time during the period.

It is appreciated that severe limitations are imposed on the significance which can be attributed to data derived from a general practitioner's consulting-room in respect of a heterogeneous group of persons, many of whom are already selected by virtue of consulting a doctor. At the same time, the information relating to this consecutive series of patients is so striking that it was thought to be worth publishing at this stage. We hope by this means to interest others who may be working in parallel fields and may be able to assist us in the extension of our studies.

\section{Method of Assessment at First Attendance}

On the occasion of the first attendance at the surgery during the study period certain social and clinical data were recorded in a standard fashion.

The social data included the patient's name, age, sex, civil status, religion, length of stay in lodging-house, contact with other relatives, occupation, occupational state, and source of income.

The clinical data were obtained by a rigidly standardized history-taking. Because of his dual role of providing medical care and taking part in a planned survey the doctor was, however, free to supplement this questionary and to carry out such physical examination as he regarded as clinically relevant to the patient's presenting symptoms. He was also, of course, free to use information acquired in respect of those patients who had already been seen at some time before the survey began.

The clinical impression derived from years of experience with lodging-house patients was that there is an unusually high inci- 
dence of chronic bronchitis, pulmonary tuberculosis (mainly quiescent), chronic alcoholism, epilepsy, gross mental illness which had required inpatient treatment, arthritis, cardiovascular disease, and major and chronic disease of the central nervous system. These patients often present with major organic and psychiatric conditions which are either static, with permanent sequelae, or are progressive and irremediable. This is in contrast with patterns of consultation in a less-selected general practice population, where there are usually a substantial number of acute, self-limiting, and simple, resolving conditions. With this in mind, after a series of pilot investigations, we devised an abbreviated method of history-taking which would enable us, for the purpose of this study, to identify at the initial consultation individuals who could be placed in one or more of 10 categories. The criteria to be satisfied in respect of each of these ten conditions were arbitrarily defined. The 10 conditions were used for the purpose of this study as diagnoses to be established or rejected at the first consultation with each patient. These were not regarded as fully established final diagnoses in the classic sense, but the criteria were rigid enough to identify certain gross pathological conditions in this group of patients. The criteria used for this first screening examination were as follows :

Chronic Bronchitis.-A history of cough and spit of at least two years' duration either continuously or at least throughout the winter months.

Pulmonary Tuberculosis.-Pulmonary tuberculosis diagnosed at any stage in the patient's life and confirmed radiologically, provided it had progressed beyond the primary complex stage.

Cardiac Disease.-This is recorded only when one or more of the following are present in patients under the age of 65: congenital heart disease ; valvular disease of the heart ; angina pectoris; coronary thrombosis; congestive cardiac failure.

Arthritis.-Any form of arthritis in which the diagnosis has been made in hospital and/or has been confirmed by $x$-ray examination.

Malignant Disease.-Patients in whom malignant disease has at any time in the past been diagnosed by a doctor.

Mental Illness.-Earlier experience with patients reporting from common lodging-houses suggested that there was a high incidence of gross psychiatric disorder and many individuals with multiple pathology. It was frequently almost impossible to distinguish between cause and effect when considering, for example, the clinical diagnosis in a man with a long history of fits who had for several years failed to maintain himself in employment, was a chronic alcoholic, and had been discharged from the Services as a "psychopathic personality." It was decided for the purpose of this study to ignore or exclude simple uncomplicated neuroses or behavioural disorders as such and to seek evidence only of gross psychiatric disturbance. For this purpose we decided to treat the following four conditions as a group-namely, mental defect, chronic alcoholism, epilepsy, and psychiatric disorder. The criteria used were as follows:

Mental Defect: Patients in whose case there is evidence that they have been found previously by formal test to have an I.Q. below 70 or who have attended a special school for the mentally handicapped or have been inmates of an institution for the mentally handicapped.

Chronic Alcoholism: Patients who concede that excessive consumption of alcohol sustained over a period has been associated with one or more of the following-loss of employment, break-up of family, imprisonment, or recurrent ill-health.

Epilepsy: Patients who have had a diagnosis of grand mal made by a doctor and for which treatment has been prescribed. When this diagnosis was accepted by the interviewing general practitioner "epilepsy" was recorded.

Other Psychiatric Disorders: Any person who has been an inpatient in a mental hospital.

These four conditions were for the purpose of this study recorded as if they were mutually exclusive. "Psychiatric disorder" is therefore limited to patients who have been in a mental hospital at some time in the past and who have not been placed in one of the other three categories.

Central Nervous System.-Any organic disease of the central nervous system not included in the above.

All of these 10 conditions had to be sufficiently advanced to satisfy the criteria laid down for the screening procedure at the brief initial examination. Our findings are therefore likely to underestimate the prevalence of these diseases in this series of patients.

\section{Data Collected at Surgery Consultations}

It is to be pointed out that, apart from the screening carried out at the initial contact with each patient, the routine work of diagnosis and treatment continued at any subsequent attendance. For study purposes, however, certain additional data were recorded at the first and at any subsequent consultation with these patients. This information was collected in loose-leaf ledger form and included, for each contact with the patient, the doctor's diagnosis at that consultation and the action taken by him in respect of prescribing, certification, and referral to hospital or to statutory or voluntary social agencies.

We can now answer three questions about this consecutive series of 310 persons-namely, What kind of people were they? What kind of diseases did they present? What picture emerges from an examination of their patterns of consultation?

\section{Findings}

\section{What Kind of Persons?}

The basic social characteristics of this series of patients are set out in Tables I to V. The main features are as follows: males outnumber females by 4 to 1 ; nearly half of the patients are in

\begin{tabular}{|c|c|c|c|c|c|}
\hline & \multicolumn{2}{|c|}{ TABLE } & I.-Age and & Sex Distribution & \multirow{2}{*}{ Total $(\%)$} \\
\hline \multicolumn{3}{|c|}{ Age in Years } & Males (\%) & Females $(\%)$ & \\
\hline $\begin{array}{l}\text { Under } 25 \\
25-45 \\
45-65 \\
65+\end{array}$ & $\begin{array}{l}\ldots \\
\cdots \\
\cdots\end{array}$ & $\begin{array}{l}\ldots \\
\cdots \\
\cdots\end{array}$ & $\begin{array}{r}4 \cdot 4 \\
27 \cdot 5 \\
50 \cdot 6 \\
17 \cdot 5\end{array}$ & $\begin{array}{r}6.8 \\
33.9 \\
42.4 \\
16.9\end{array}$ & $\begin{array}{r}4 \cdot 8 \\
28 \cdot 7 \\
49 \cdot 0 \\
17 \cdot 4\end{array}$ \\
\hline \multicolumn{2}{|c|}{ Total $(=100 \%)$} & .. & 251 & 59 & 310 \\
\hline
\end{tabular}

TABle II.-Duration in Residence at Present Address

\begin{tabular}{|c|c|c|c|c|c|}
\hline \multicolumn{3}{|c|}{ Length of Stay } & \multirow{2}{*}{$\begin{array}{c}\text { Males (\%) } \\
24 \cdot 7 \\
13.1 \\
19.9 \\
10.8 \\
16.7 \\
14.8 \\
\end{array}$} & \multirow{2}{*}{$\begin{array}{c}\text { Females }(\%) \\
23.7 \\
23.7 \\
13.6 \\
8.5 \\
13.6 \\
16.9 \\
\end{array}$} & \multirow{2}{*}{$\begin{array}{c}\text { Total (\%) } \\
24.5 \\
15.2 \\
18.7 \\
10.3 \\
16.1 \\
15.2 \\
\end{array}$} \\
\hline $\begin{array}{l}\text { Under } 1 \text { week } \\
1-4 \text { weeks } \\
1-6 \text { months } \\
6-12 \text { " } \\
1-5 \text { years } \\
5+\text { " }\end{array}$ & $\begin{array}{l}\cdots \\
\cdots \\
\cdots \\
\cdots \\
\cdots\end{array}$ & \begin{tabular}{l|}
$\cdots$ \\
$\cdots$ \\
$\cdots$ \\
$\cdots$
\end{tabular} & & & \\
\hline \multicolumn{2}{|c|}{ Total $(=100 \%)$} & $\cdots$ & 251 & 59 & 310 \\
\hline
\end{tabular}

TABLE III.-Marital Status

\begin{tabular}{lll|c|c|c}
\multicolumn{2}{c|}{ Marital Status } & Males (\%) & Females (\%) & Total (\%) \\
\hline Married. & $\ldots$ & $\ldots$ & 6.4 & 16.9 & 8.4 \\
Single & $\ldots$ & $\ldots$ & 60.5 & 33.9 & 55.5 \\
Widowed & $\ldots$ & $\ldots$ & 10.0 & 10.2 & 10.0 \\
Divorced & $\ldots$ & $\ldots$ & 3.2 & 5.1 & 3.5 \\
Separated & $\ldots$ & $\ldots$ & 19.9 & 33.9 & 22.6 \\
\hline \multicolumn{2}{c|}{ Total (=100\%) } & $\ldots$ & 251 & 59 & 310 \\
\hline
\end{tabular}

TABLB IV.-Employment Status

\begin{tabular}{|c|c|c|c|c|}
\hline \multicolumn{2}{|c|}{ Employment Status } & \multirow{2}{*}{$\begin{array}{c}\text { Males (\%) } \\
33.1 \\
55.0 \\
11.9 \\
\end{array}$} & \multirow{2}{*}{$\begin{array}{c}\text { Females.(\%) } \\
15.2 \\
64.5 \\
20.3 \\
\end{array}$} & \multirow{2}{*}{$\begin{array}{c}\text { Total }(\%) \\
29 \cdot 7 \\
56 \cdot 8 \\
13.5 \\
\end{array}$} \\
\hline $\begin{array}{l}\text { Employed } \\
\text { Unemployed } \\
\text { Retired ... }\end{array}$ & $\begin{array}{l}\cdots \\
\cdots \\
\end{array}$ & & & \\
\hline Total $(=$ & $00 \%) \quad \ldots$ & 251 & 59 & 310 \\
\hline
\end{tabular}

TABLB V-Source of Income

\begin{tabular}{cc|c|c|c}
\hline Income Source & & Males (\%) & Females (\%) & Total (\%) \\
\hline Wage & $\ldots$ & 32.7 & 15.2 & 29.4 \\
National Insurance & $\ldots$ & 16.7 & 5.1 & 14.5 \\
National Assistance & $\ldots$ & 41.1 & 61.0 & 44.9 \\
Old age pension & $\ldots$ & 13.5 & 15.2 & 13.8 \\
Other income &.. & 2.8 & 11.9 & 4.5 \\
\hline Total $(=100 \%)$ & $\ldots$ & 251 & 59 & 310 \\
\hline
\end{tabular}


the age group 45 to 65 years; a quarter had been resident for less than one week, while $38 \%$ of males and $47 \%$ of females trad been resident for less than four weeks at the time of consultation-for both sexes $58 \%$ had been resident under six months, though $31 \%$ had been residing in a particular lodginghouse for more than one year.

Sixty-one per cent. of males but only $34 \%$ of females were single. However, $23 \%$ of males and $39 \%$ of females were either divorced or legally or socially separated from their spouses. Thirty-three per cent. of male and $15 \%$ of females were gainfully employed at the time of consultation, but $55 \%$ of males and $65 \%$ of females were unemployed. Seventy per cent. of males and $52 \%$ of females were classified as unskilled, using the General Register Office classifications. Table V indicates that $59 \%$ were in receipt of National Insurance or National Assistance benefits. Nearly half of the patients stated that they had no contact with any member of their family.

This consecutive series of consulting patients presents, therefore, a very different picture from what is offered by 300 consecutive consulting patients in the average general practice (General Register Office, 1956). The preponderance of males (particularly over the age of 45), their social mobility, their precarious financial status, and their social isolation are all striking features.

\section{What Kind of Diseases did they Present ?}

Table VI lists the frequency with which any of the selected list of 10 conditions was recorded at the initial examination. A striking feature is the incidence of chest conditions and gross mental illness. Fifty-four (17\%) had chronic bronchitis. Thirty-two patients $(10 \%)$ had at one time been diagnosed as having pulmonary tuberculosis. In half of these the condition was healed or quiescent, but 17 were still under surveillance, of whom seven were undergoing active treatment.

\begin{tabular}{|c|c|c|c|}
\hline Group 1 Disease & Males (\%) & Females (\%) & Total (\%) \\
\hline 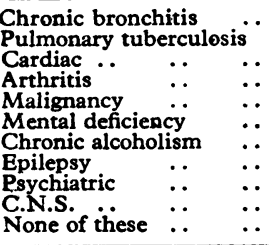 & $\left.\begin{array}{r}17.5 \\
11.9 \\
4.8 \\
8.4 \\
4.4 \\
1.6 \\
9.6 \\
5.2 \\
11.5 \\
7.2 \\
41.0\end{array}\right\}^{27.9}$ & $\left.\begin{array}{r}17 \cdot 0 \\
3 \cdot 4 \\
6 \cdot 8 \\
10 \cdot 2 \\
3 \cdot 4 \\
3 \cdot 4 \\
8 \cdot 5 \\
1 \cdot 7 \\
15 \cdot 2 \\
5 \cdot 1 \\
42 \cdot 4\end{array}\right\} 28 \cdot 8$ & $\left.\begin{array}{r}17 \cdot 4 \\
10 \cdot 3 \\
5 \cdot 2 \\
8 \cdot 7 \\
4 \cdot 2 \\
1 \cdot 9 \\
9 \cdot 4 \\
4.5 \\
12 \cdot 3 \\
6 \cdot 8 \\
41 \cdot 3\end{array}\right\} 28 \cdot 1$ \\
\hline Total $(100 \%)$ & 251 & 59 & 310 \\
\hline
\end{tabular}

Attention is drawn to the prevalence of malignant disease. In respect of 13 patients ( $4 \%$ of the series) malignant disease was recorded. Many of these patients were of course known to have been previously diagnosed in a hospital or clinic before reporting for the first time to this practice. In eight of the 13 the site of the primary growth was the lung, in two the large bowel, and in one each the pharynx, the skin, and lymph nodes. Five of them died during the period of the survey.

Eighty-seven patients. (28\%) satisfied the criteria for being included in the group showing gross manifestation of mental illness, 38 having gross psychiatric illness, while 29 conceded that chronic alcoholism was a major problem.

In the whole series six out of 10 patients satisfied the criteria for inclusion in one or more of these 10 selected major illness categories.

\section{Consultation Patterns}

During the six-month period the 310 patients accounted for 1,422 consultations. At each consultation the doctor recorded one clinical diagnosis. It is emphasized that this was the doctor's own diagnosis, written in his own words in the course of routine clinical practice, as contrasted with the arbitrarily defined list of 10 conditions referred to above for use at the first examination. The doctor's consultation diagnoses were coded, the full international list being used, then grouped into one or other of the 16 main sections of this list. While because of the mobility of some of these patients it is not possible to give consultation rates on patients at risk for a specified period of time, an analysis of these consultation diagnoses gives additional information about the spectrum of disease presented by this consecutive series of patients. The results are given in summary in Table VII. This illustrates the preoccupation of the doctor during his routine consulting sessions with mental illness, respiratory disease (in particular chronic bronchitis and the sequelae of pulmonary tuberculosis), diseases of the musculoskeletal system, and the after-effects of injury and violence. Also in contrast with more usual patterns of consultation in general practice is the relatively low number of consultations for upper respiratory infection.

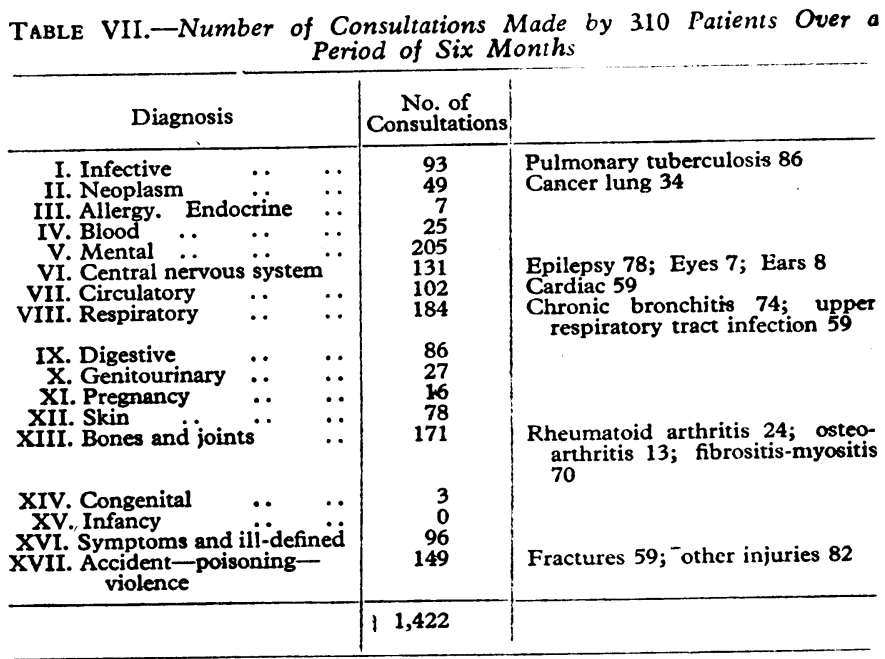

The relevance of mental illness to consultation patterns is again probably underrepresented in Table VII, since at least some of the consultations which were attributable to ill-defined symptoms and some of the consultations given such labels as "fibrositis," "myositis," and some of the consultations labelled epilepsy would require to be looked at more closely in order to present a precise picture of the proportion of consultations which could be attributed to the mental-illness group.

Therapeutic Action.-An analysis of the action taken by the doctor at these 1,422 consultations in respect of prescribing, certification, and referral to hospital or other agencies is given in Table VIII. At more than half of the consultations the patient received a certificate, and at less than half was a prescription given-a high certificate rate and a low prescribing rate for general practice (General Register Office, 1956). At 135 consultations $(9.8 \%)$ the patient was referred to hospital. This represents a high referral rate compared with $3.1 \%$ found in another study in this practice (Scott et al., 1960).

It is pointed out that previous or coexisting attendance at hospital departments was used as part of the criteria for establishing the diagnosis of one or more of the selected list of diseases. Our high referral rate of $9.8 \%$ is therefore an under-

TABLE VIII-Referrals

\begin{tabular}{|c|c|c|c|c|}
\hline Action Taken & & & & $\%$ of Consultations \\
\hline $\begin{array}{l}\text { Prescription issued } \\
\text { Certificate \#” } \\
\text { Referral to hospital } \\
\text { „social agency }\end{array}$ & $\begin{array}{l}\cdots \\
\cdots \\
\cdots\end{array}$ & $\begin{array}{l}\cdots \\
\cdots \\
\cdots\end{array}$ & $\begin{array}{l}\cdots \\
\therefore \\
\therefore\end{array}$ & $\begin{array}{r}43 \cdot 3 \\
52 \cdot 3 \\
9 \cdot 8 \\
5 \cdot 0\end{array}$ \\
\hline
\end{tabular}

Total consultations $(=100 \%), 1,422$. 
estimate of the use made of hospital services for this group of patients, since many had been attending before being seen by us and did not require a new referral. Forty per cent. of the patients in this series had attended a hospital outpatient department on at least one occasion during the survey period, and at $36 \%$ of all consultations the patient was at that point in time actually attending one or other of the local hospital outpatient departments. Furthermore, it is common experience that many individuals residing in common lodging-houses when taken suddenly ill or suffering from acute traumatic episodes either report direct to the casualty department or are taken there by the police. This group of patients, therefore, are high consumers of hospital outpatient services.

\section{Comment}

In this study we have attempted to obtain some objective data to support or refute earlier clinical impressions of the patterns of pathology presented to a general practitioner by patients residing in common lodging-houses.

The technique used by the general practitioner in screening patients at their first attendance requires further study and evaluation. In a second series each new patient, in addition to being seen by the general practitioner, is being examined independently by another doctor. This examination includes the recording of blood pressure, chemical and bacteriological examination of the urine, routine haematology, liver-function tests, blood urea, and syphilis flocculation reaction, as well as routine cardiography and chest radiography. These patients also have presented to them a standardized psychiatric questionary-symptom-sign inventory (Foulds and Caine, 1965). We will use some of this material to check the validity of the simpler clinical screening.

As in our preliminary study, most of the reported studies of lodging-house patients deal with categories of individuals already selected because they have consulted a particular medical or social agency. To obtain a more balanced picture of the quantitative and qualitative aspects of the problem we require to apply social and epidemiological methods to the population as a whole or to a suitable random sample. Such a study has now been planned.

We cannot generalize from this material to the lodging-house population as a whole, since we do not know the factors which determine the selection of patients coming to our consultingroom. Nevertheless, the evidence we present in this paper is that at least a proportion of these patients are highly mobile, are social isolates, and are high consumers of medical and social services. It is suggested that some attention might profitably be given to the problems of communication between hospital outpatient departments, as well as between these departments and the general practitioner and statutory or voluntary agencies in the community, so as to minimize unnecessary referral and unnecessary repetition of examinations and tests.

\section{Summary}

The results are given of a study of a consecutive series of 310 individuals who were resident in common lodging-houses in Edinburgh and who had consulted a local general practice. In this series males outnumbered females by four to one. A high proportion $(26 \%)$ were divorced or separated from their spouses, many were highly mobile, and most were social isolates. This group showed a high incidence of chronic bronchitis and of pulmonary tuberculosis and its sequelae. Some $28 \%$ had gross mental illness and $4 \%$ were found to have malignant disease. Apart from these conditions a high proportion of the consultations were for the late effects of trauma. The group as a whole were high consumers of medical and social services. At $10 \%$ of consultations the patient was referred to the hospital services. Forty per cent. of the patients had attended a hospital department at least once during the six-month period of the survey.

A method is described by which a doctor may carry out a simple screening of patients from common lodging-houses whom he is seeing for the first time. This is essentially a sharply focused history, but the results in the series would appear, so far at least, to justify the adoption of the method either by a general practitioner or by a doctor working in a casualty or outpatient department.

Two of us (P.G.G. and D.C. M.) were responsible for the clinical examination and recording, but we are all three indebted to our colleagues in the department, in particular Dr. C. A. Gibbs and Miss E. A. Warren, for advice and criticism in planning a series of studies of which this is the first.

\section{REFERENCES}

Edwards, G., Hawker, A., Williamson, V., and Hensman, C. (1966). Lancet, 1, 249.

Foulds, G. A., and Caine, T. M. (1965). Personality and Personal Illness. London.

General Register Office (1956). Studies on Medical and Population Subjects, No. 9. H.M.S.O., London.

Laidlaw, S. I. A. (1956). Glasgow Common Lodging Houses and the People Living in Them. Glasgow.

Sargaison, E. Miriam (1954). Growing Old in Common Lodgings. London.

Scott, R. Anderson, J. A. D., and Cartwright, A. (1960). Brit. med. J., $2,293$.

Turner, M. (1960). Forgotten Men. London.

Whiteley, J. S. (1955). Lancet, 2, 608. 